Original paper

\title{
Ammonia-induced mitochondrial impairment is intensified by manganese co-exposure: relevance to the management of subclinical hepatic encephalopathy and cirrhosis-associated brain injury
}

\author{
Reza Heidari', Akram Jamshidzadeh², Mohammad Mehdi Ommati', Elaheh Rashidi², Forouzan Khodaei ${ }^{2}$, Ala Sadeghi², \\ Arghavan Hosseini², Hossein Niknahad ${ }^{1,2}$
}

'Pharmaceutical Sciences Research Center, Shiraz University of Medical Sciences, Shiraz, Iran

2Department of Pharmacology and Toxicology, School of Pharmacy, Shiraz University of Medical Sciences, Shiraz, Iran

\begin{abstract}
Aim of the study: Hepatic encephalopathy (HE) is a neuropsychiatric syndrome ensuing from liver failure. The liver is the major site of ammonia detoxification in the human body. Hence, acute and chronic liver dysfunction can lead to hyperammonemia. Manganese $(\mathrm{Mn})$ is a trace element incorporated in several physiological processes in the human body. $\mathrm{Mn}$ is excreted through bile. It has been found that cirrhosis is associated with hyperammonemia as well as body $\mathrm{Mn}$ accumulation. The brain is the primary target organ for both ammonia and $\mathrm{Mn}$ toxicity. On the other hand, brain mitochondria impairment is involved in the mechanism of $\mathrm{Mn}$ and ammonia neurotoxicity.

Material and methods: The current study was designed to evaluate the effect of $\mathrm{Mn}$ and ammonia and their combination on mitochondrial indices of functionality in isolated brain mitochondria. Isolated brain mitochondria were exposed to increasing concentrations of ammonia and $\mathrm{Mn}$ alone and/or in combination and several mitochondrial indices were assessed.

Results: The collapse of mitochondrial membrane potential, increased mitochondrial permeabilization, reactive oxygen species formation, and a significant decrease in mitochondrial dehydrogenase activity and ATP content were evident in Mn-exposed (0.005-1 mM) brain mitochondria. On the other hand, ammonia (0.005-0.5 mM) caused no significant changes in brain mitochondrial function. It was found that co-exposure of the brain mitochondria to $\mathrm{Mn}$ and ammonia causes more evident mitochondrial impairment in comparison with $\mathrm{Mn}$ and/or ammonia alone.

Conclusions: These data indicate additive toxicity of ammonia and $\mathrm{Mn}$ in isolated brain mitochondria exposed to these neurotoxins.
\end{abstract}

Key words: brain injury, cirrhosis, energy crisis, hepatic encephalopathy, locomotor dysfunction.

\section{Address for correspondence}

Dr. Reza Heidari and Dr. Hossein Niknahad, Shiraz University of Medical Sciences, P. 0. Box 1583; 71345, Roknabad, Karafarin St., Shiraz, Iran, e-mail: rezaheidari@hotmail.com and niknahadh@sums.ac.ir

\section{Introduction}

Hepatic encephalopathy (HE) is a deleterious clinical complication accompanying acute and chronic liver injury [1]. Although the exact cause of HE is not known, there is agreement on the predominant role of ammonia in the pathogenesis of HE-associated complications [2]. Ammonia is metabolized in the urea cycle by the liver. Damaged livers are unable to metabolize ammonia. Hence, this chemical reaches toxic levels in the systemic circulation. Brain tissue is susceptible to high ammonia concentrations [3, 4]. Ammonia 
is a neurotoxin that mostly influences astrocytes in the central nervous system (CNS) $[5,6]$. Several direct toxic effects of ammonia on neurons have also been characterized [6]. Ammonia causes brain edema, oxidative stress, and inflammation when its level rises during HE [7]. Consequently, a decline in brain function occurs in patients with HE [7]. Hyperammonemia also affects hepatocytes and liver function [8].

Oxidative stress and its subsequent deleterious events have been recognized as the primary mechanisms for ammonia-induced neurotoxicity [5, 9]. On the other hand, ammonia is a mitochondrial toxin [10-12]. It has been reported that mitochondrial function is impaired and brain energy metabolism is interrupted in chronic and acute models of $\mathrm{HE}$ [13-15]. Ammonia negatively affects several vital enzymes that are responsible for energy metabolism in mitochondria [16]. Asymptomatic hepatic encephalopathy due to chronic liver injury, hepatitis, mild cirrhosis, known as "minimal hepatic encephalopathy" or "subclinical hepatic encephalopathy" (SCHE), is a complication which represents as a subclinical elevation in plasma ammonia level $[17,18]$. Memory loss, locomotor dysfunction, stupor, and defect in intellectual function are attributed to SCHE [17, 18]. A high rate of SCHE is associated with liver injury and cirrhosis [17, 18]. All these events could affect patients' quality of life.

Manganese $(\mathrm{Mn})$ is an essential trace element incorporated in the structure of several enzymes and metabolic pathways in humans [19]. On the other hand, it has been documented that excess Mn exposure is toxic especially toward the CNS [20-22]. Mn-induced neurotoxicity is clinically revealed as locomotor dysfunction and a Parkinsonism-like syndrome [23, 24]. Oxidative stress and defect in the brain tissue antioxidant systems have been revealed in Mn models of neurotoxicity [21, 25-28]. On the other hand, it has been found that Mn exposure significantly worsened mitochondrial function [25, 29-32].

It has been found that $\mathrm{Mn}$ excretion is disturbed in cirrhotic patients [23, 33-36]. As Mn is excreted in the bile, any defect in bile excretion leads to a high body Mn level. A several-fold increase in blood and brain tissue level of Mn has been found in cirrhosis [23, 3336]. Hence, high brain Mn might play a role in cirrhosis-associated CNS injury.

The current study aimed to evaluate the effect of non-toxic concentrations of ammonia alone or in combination with $\mathrm{Mn}$ exposure to evaluate any synergistic mitotoxicity effects of these neurotoxic chemicals. The results might help to improve clinical management of $\mathrm{HE}$-associated CNS complications especially in chronic cases (e.g., cirrhosis-associated subclinical hyperammonemia).

\section{Material and methods}

\section{Chemicals}

Sodium succinate, fatty acid-free bovine serum albumin (BSA) fraction $\mathrm{V}$, thiobarbituric acid (TBA), 4,2-hydroxyethyl,1-piperazineethanesulfonic acid (HEPES), manganese chloride, dimethyl sulfoxide (DMSO), ammonium chloride, D-mannitol, 3-(N-morpholino)-propane sulfonic acid (MOPS), n-butanol, 3-[4,5dimethylthiazol-2-yl]-2,5-diphenyltetrazolium bromide (MTT), 2',7'dichlorofluorescein (DCF), sucrose, rhodamine 123 (Rh 123), Coomassie brilliant blue, and ethylene glycol-bis-(2-aminoethyl ether)-N,N,N'N'-tetraacetic acid (EGTA) were obtained from Sigma Chemical Co. (St. Louis, MO, USA). Hydroxymethyl aminomethane hydrochloride (Tris-HCl) and trichloroacetic acid (TCA) were purchased from Merck (Darmstadt, Germany). All salts for preparing buffers were of the analytical grade and obtained from Merck (Darmstadt, Germany).

\section{Animals}

Male C57BL/6 mice (20-25 g) were housed in cages on wood bedding (temperature of $23 \pm 1^{\circ} \mathrm{C}$; relative humidity of $40 \%$ ). Animals had free access to tap water and a standard chow diet. Animals received human care and were handled according to the animal handling protocols which were approved by the Institutional Animal Experiment Committee of Shiraz University of Medical Sciences (\#95-01-36-12832).

\section{Brain mitochondria isolation}

Brain mitochondria were isolated by the differential centrifugation method as previously described [37, 38]. Briefly, animals were euthanized by cervical dislocation, and their brain was rapidly excised and immersed in ice-cooled $\left(4^{\circ} \mathrm{C}\right)$ isolation buffer containing $225 \mathrm{mM}$ mannitol, $1 \mathrm{mM}$ EGTA, $75 \mathrm{mM}$ sucrose, $5 \mathrm{mM}$ HEPES, $0.1 \%$ essentially fatty acid-free bovine serum albumin $(\mathrm{pH}=7.4)$ at a $10: 1$ buffer-to-tissue $(\mathrm{v}: \mathrm{w})$ ratio [37-39]. The brain was homogenized, and the tissue homogenate was centrifuged $(600 \mathrm{~g}$ for $10 \mathrm{~min}$ at $\left.4^{\circ} \mathrm{C}\right)$ to remove intact cells and nuclei. The supernatants were further centrifuged $\left(12,000 \mathrm{~g}, 8 \mathrm{~min}, 4^{\circ} \mathrm{C}\right)$ to precipitate the heavy membrane fractions (mitochondria) [38]. The recent step was repeated three times using the fresh mitochondria isolation buffer medium 
to increase mitochondrial yield. As mentioned, all manipulations for mitochondria isolation were performed at $4^{\circ} \mathrm{C}$ or on ice to minimize mitochondrial injury $[37,38]$.

\section{Mitochondrial membrane potential}

Mitochondrial uptake of rhodamine 123 as a fluorescent probe was used for the estimation of mitochondrial depolarization [37, 40-42]. Briefly, the mitochondrial fractions $(1 \mathrm{mg}$ protein $/ \mathrm{ml}$ ) were incubated with $10 \mu \mathrm{l}$ of rhodamine 123 (final concentration of $10 \mu \mathrm{M}$ ) in a buffer containing $125 \mathrm{mM}$ sucrose, $10 \mathrm{mM}$ HEPES, $65 \mathrm{mM} \mathrm{KCl}, \mathrm{pH}=7.2\left(30 \mathrm{~min}, 37^{\circ} \mathrm{C}\right.$, in the dark). Afterward, samples were centrifuged $(15,000 \mathrm{~g}$, $5 \mathrm{~min}, 4^{\circ} \mathrm{C}$ ) and the fluorescence intensity of the supernatant was monitored using a FLUOstar Omega (BMG Labtech, Germany) multifunctional microplate reader at the excitation and emission wavelength of $\lambda=485 \mathrm{~nm}$ and $\lambda=525 \mathrm{~nm}$, respectively [37].

\section{Mitochondrial swelling assay}

Mitochondrial swelling was measured as previously described [37]. Briefly, the isolated mitochondria samples $(0.1 \mathrm{mg}$ protein $/ \mathrm{ml})$ were suspended in a buffer containing $125 \mathrm{mM}$ sucrose, $10 \mathrm{mM}$ HEPES, $65 \mathrm{mM} \mathrm{KCl}$, and $\mathrm{pH}=7.2$. The light absorbance (at $\lambda=540 \mathrm{~nm}$ ) was monitored (30 min, 1-minute intervals) using an Epoch plate reader (BioTek Instruments, Highland Park, USA) with constant shaking and temperature control $\left(30^{\circ} \mathrm{C}\right)[37,43]$. It is accepted that decreased light absorbance is consistent with an increase in mitochondrial volume. Hence, as mitochondria become more swollen, the differences between the light absorbance of two time points ( $\triangle \mathrm{OD} 540 \mathrm{~nm}$ ) increase $[37,44]$.

\section{Mitochondrial dehydrogenase activity}

The 3-(4,5-dimethylthiazol-2-yl)-2,5-diphenyltetrazolium bromide (MTT) assay was applied as a colorimetric method for determination of mitochondrial dehydrogenase activity in isolated mouse brain mitochondria [44-46]. Briefly, mitochondrial suspension ( $1 \mathrm{mg}$ protein/ml) in a buffer containing $220 \mathrm{mM}$ mannitol, $70 \mathrm{mM}$ sucrose, $2 \mathrm{mM}$ HEPES, and $0.5 \mathrm{mM}$ EGTA, at pH 7.4, was incubated with $0.4 \%$ of MTT at $37^{\circ} \mathrm{C}$ for $30 \mathrm{~min}$ in the dark. Samples were centrifuged $(12,000 \mathrm{~g}, 15 \mathrm{~min})$ and the pellet of purple formazan crystals was dissolved in $1 \mathrm{ml}$ dimethyl sulfoxide (DMSO). Afterward, $100 \mu \mathrm{l}$ of dissolved formazan was added to a 96-well plate, and the optical density was measured with an Epoch plate reader $(\lambda=570 \mathrm{~nm}$, BioTek Instruments, Highland Park, USA) [44]. For standardization of all data obtained in the current study, sample protein concentrations were determined by the Bradford method [47].

\section{Estimation of reactive oxygen species (ROS) in isolated brain mitochondria}

Mitochondrial ROS measurement was performed using the fluorescent probe DCFH-DA [37]. Briefly, isolated brain mitochondria were incubated in a respiratory buffer containing $65 \mathrm{mM} \mathrm{KCl}, 125 \mathrm{mM}$ sucrose, $10 \mathrm{mM}$ HEPES, $5 \mathrm{mM}$ sodium succinate, and $20 \mu \mathrm{M} \mathrm{Ca}^{2+}$, at $\mathrm{pH} 7.2$ [37]. DCFH-DA was added (final concentration, $10 \mu \mathrm{M}$ ) to mitochondria and then incubated for $30 \mathrm{~min}$ at $37^{\circ} \mathrm{C}$ in the dark. Then, the fluorescence intensity of DCF was measured using a FLUOstar Omega (BMG Labtech, Germany) multifunctional fluorescent microplate reader $\left(\lambda_{\text {excitation }}=485 \mathrm{~nm}\right.$ and $\left.\lambda_{\text {emission }}=525 \mathrm{~nm}\right)$ $[37,44]$.

\section{Mitochondrial ATP level}

A luciferase-luciferin-based kit (ENLITEN from Promega, USA) was used to assess mitochondrial ATP content [48-50]. Samples and buffer solutions were prepared based on the kit instructions. Isolated brain mitochondria $(1 \mathrm{mg} / \mathrm{ml}$ protein) were treated with $100 \mu \mathrm{l}$ of trichloroacetic acid $(0.3 \% \mathrm{w}: \mathrm{v})$ and centrifuged $\left(15,000 \mathrm{~g}, 20 \mathrm{~min}, 4^{\circ} \mathrm{C}\right)$. Afterward, $100 \mu \mathrm{l}$ of the supernatant was added to $100 \mu \mathrm{l}$ of the ATP kit and the luminescence intensity of samples was measured $(\lambda=560 \mathrm{~nm})$ using a FLUOstar Omega (BMG Labtech, Germany) multifunctional microplate reader [48-50].

\section{Statistical analysis}

Data are given as the mean $\pm \mathrm{SD}$. Data comparison was performed by one-way analysis of variance (ANOVA) with Tukey's multiple comparisons test as the post hoc test. Differences were considered statistically significant when $p<0.05$.

\section{Results}

There were no significant changes in mitochondrial dehydrogenase activity in isolated brain mitochondria exposed to ammonia up to $500 \mu \mathrm{M})$. On the other hand, concentrations of ammonia higher than $1 \mathrm{mM}$ significantly decreased mitochondrial dehydrogenase activity in comparison with the control group. $\mathrm{Mn}$ administration caused a significant decrease in 


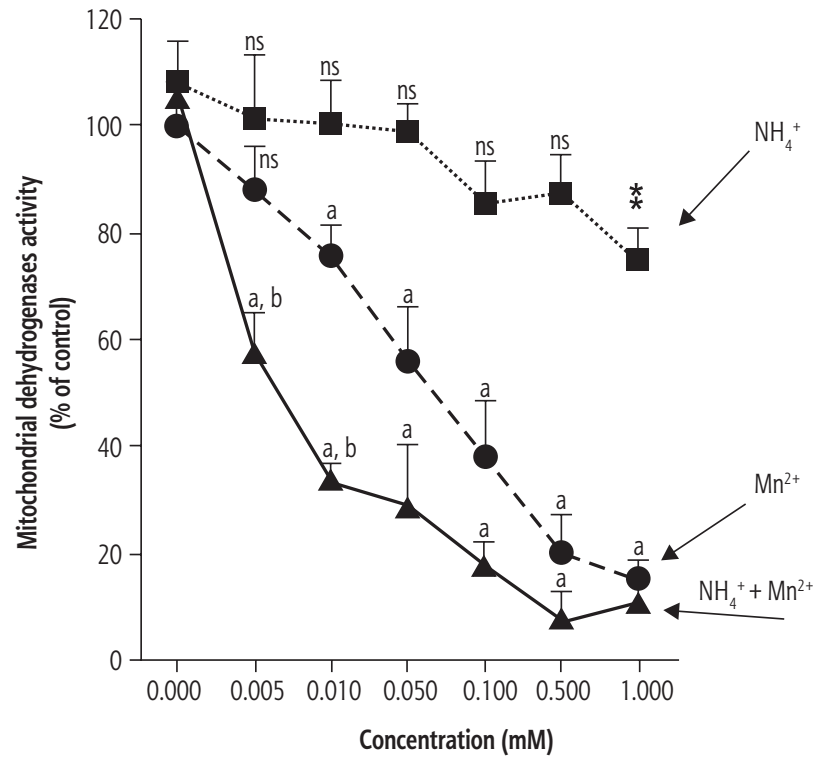

Data are presented as mean $\pm S D(n=8)$. IIndicates significantly different as compared

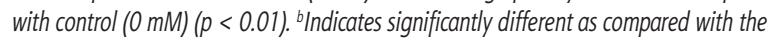
same concentration of $\mathrm{NH}_{4}^{+}$and/or $\mathrm{Mn}^{2+}$-treated mitochondria $(p<0.05)$. ns - not significant as compared with control $(0 \mathrm{mM})$.

Fig. 1. Isolated brain mitochondrial dehydrogenases activity in the presence of manganese $\left(\mathrm{Mn}^{2+}\right)$ and ammonia $\left(\mathrm{NH}_{4}^{+}\right)$

mitochondrial dehydrogenase activity even at low concentrations of this trace element. On the other hand, it was found that the effect of combined $\mathrm{Mn}$ and ammonia on brain mitochondrial dehydrogenase activity was significantly higher than the sole administration of these chemicals (Fig. 1).

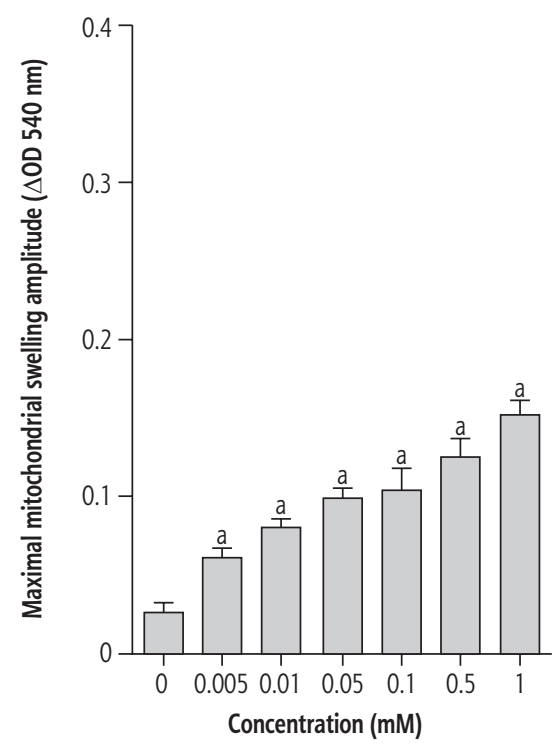

Further evaluation of mitochondrial function revealed significant mitochondrial permeabilization and swelling in the Mn-treated groups. Significant mitochondrial swelling was also identified in $1 \mathrm{mM}$ ammonia-exposed isolated brain mitochondria. On the other hand, it was found that co-exposure of $\mathrm{Mn}$ and ammonia caused significantly higher mitochondrial swelling amplitude in comparison with the $\mathrm{Mn}$ and/or ammonia-treated group (Fig. 2).

A significant collapse of mitochondrial membrane potential was evident in Mn-exposed mitochondria in comparison with the control group. Mitochondria depolarization was also detected in ammonia $1 \mathrm{mM}$ group. It was found that $\mathrm{Mn}$ and ammonia co-administration exacerbated ammonia-induced mitochondrial depolarization (Fig. 3).

Mitochondria-mediated ROS formation was hastened in Mn-treated brain mitochondria as compared with the control group. Significant ROS also was detected in the ammonia (1 mM)-treated group. On the other hand, more ROS were formed when isolated mice brain mitochondria were co-exposed to $\mathrm{Mn}$ and ammonia in comparison to the sole $\mathrm{Mn}$ and ammonia group (Fig. 4).

Mitochondria ATP content was significantly decreased when mice brain mitochondria were exposed to $\mathrm{Mn}$ (0.005-1 mM). Ammonia (1 mM) treatment also caused a significant decrease of mitochondrial ATP content in comparison with the control group. It was found that co-exposure to $\mathrm{Mn}$ and ammonia caused significant depletion of mitochondrial ATP content in

Data are given as mean $\pm S D(n=8)$. ${ }^{a}$ Indicates significantly different as compared with control $(0 \mathrm{mM})(p<0.01)$. ${ }^{b}$ Indicates significantly different as compared with the same concentration of $\mathrm{NH}_{4}^{+}$and/or $\mathrm{Mn}^{2+}$-treated mitochondria $(\mathrm{p}<0.05)$. ns - not significant as compared with control $(0 \mathrm{mM})$.

Fig. 2. Ammonia $\left(\mathrm{NH}_{4}^{+}\right)$and manganese $\left(\mathrm{Mn}^{2+}\right)$-induced mitochondrial swelling and permeabilization 

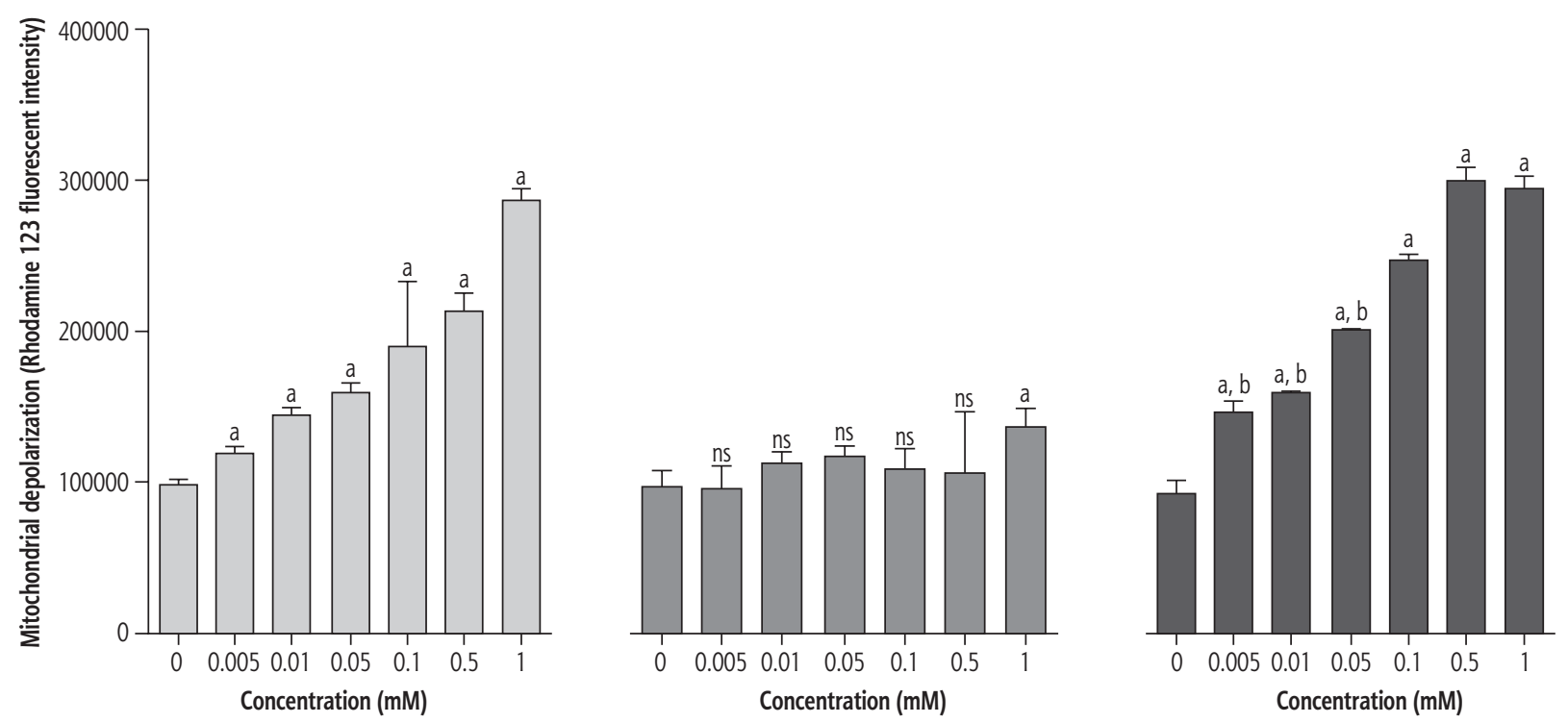

Data are shown as mean $\pm S D(n=8)$. Indicates significantly different as compared with control $(0 \mathrm{mM})(p<0.01)$. ${ }^{b} / n$ dicates significantly different as compared with the same concentration of $\mathrm{NH}_{4}^{+}$and/or $\mathrm{Mn}^{2+}$-treated mitochondria $(\mathrm{p}<0.05)$. $\mathrm{ns}$ - not significant as compared with control $(0 \mathrm{mM})$.

Fig. 3. Mitochondrial depolarization in the presence of ammonia $\left(\mathrm{NH}_{4}^{+}\right)$and manganese $\left(\mathrm{Mn}^{2+}\right)$
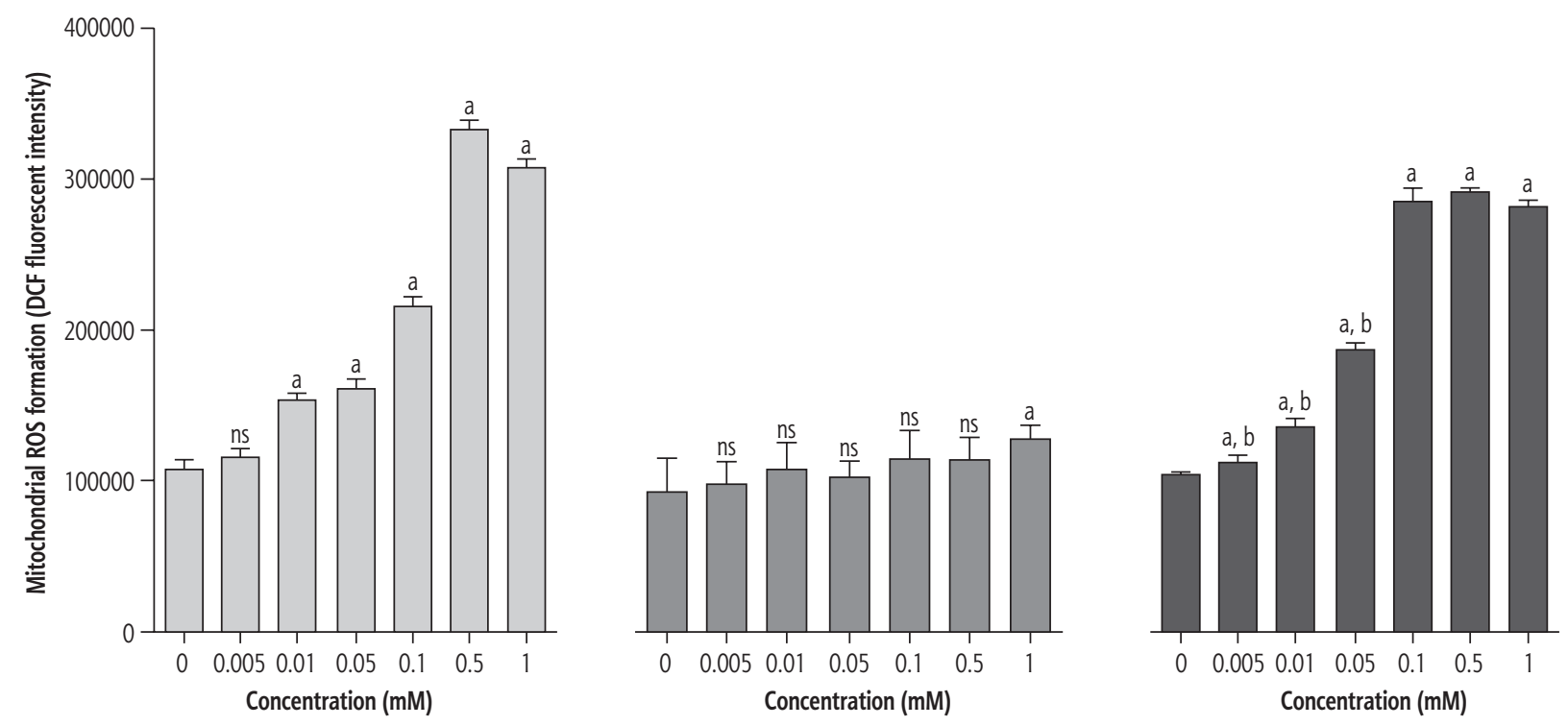

$\square \mathrm{Mn}^{2+} \quad \square \mathrm{NH}_{4}^{+} \quad \square \mathrm{Mn}^{2+}+\mathrm{NH}_{4}^{+}$

Data are shown as mean $\pm S D(n=8)$. Indicates significantly different as compared with control $(0 \mathrm{mM})(p<0.01) .{ }^{b}$ Indicates significantly different as compared with the same concentration of $\mathrm{NH}_{4}^{+}$and/or $\mathrm{Mn}^{2+}$-treated mitochondria $(\mathrm{p}<0.05)$. $\mathrm{ns}$ - not significant as compared with control $(0 \mathrm{mM})$.

Fig. 4. Increased mitochondrial reactive oxygen species level in the presence of manganese $\left(\mathrm{Mn}^{2+}\right)$ and ammonia $\left(\mathrm{NH}_{4}{ }^{+}\right)$

comparison with $\mathrm{Mn}$ and/or ammonia-treated groups (Fig. 5).

\section{Discussion}

Chronic liver injury and cirrhosis are the typical outcomes of a variety of liver diseases and toxic insults.
Cirrhosis is a chronic liver injury with multifaceted clinical features. It has been well documented that cirrhosis is associated with chronic hepatic encephalopathy (HE). Cirrhosis-associated HE is characterized as disturbances in locomotor function, fatigue, the decline in intellectual capacity, sleep disturbances, and altered patient mood [51-54]. All these changes affect patients' quality of life. 

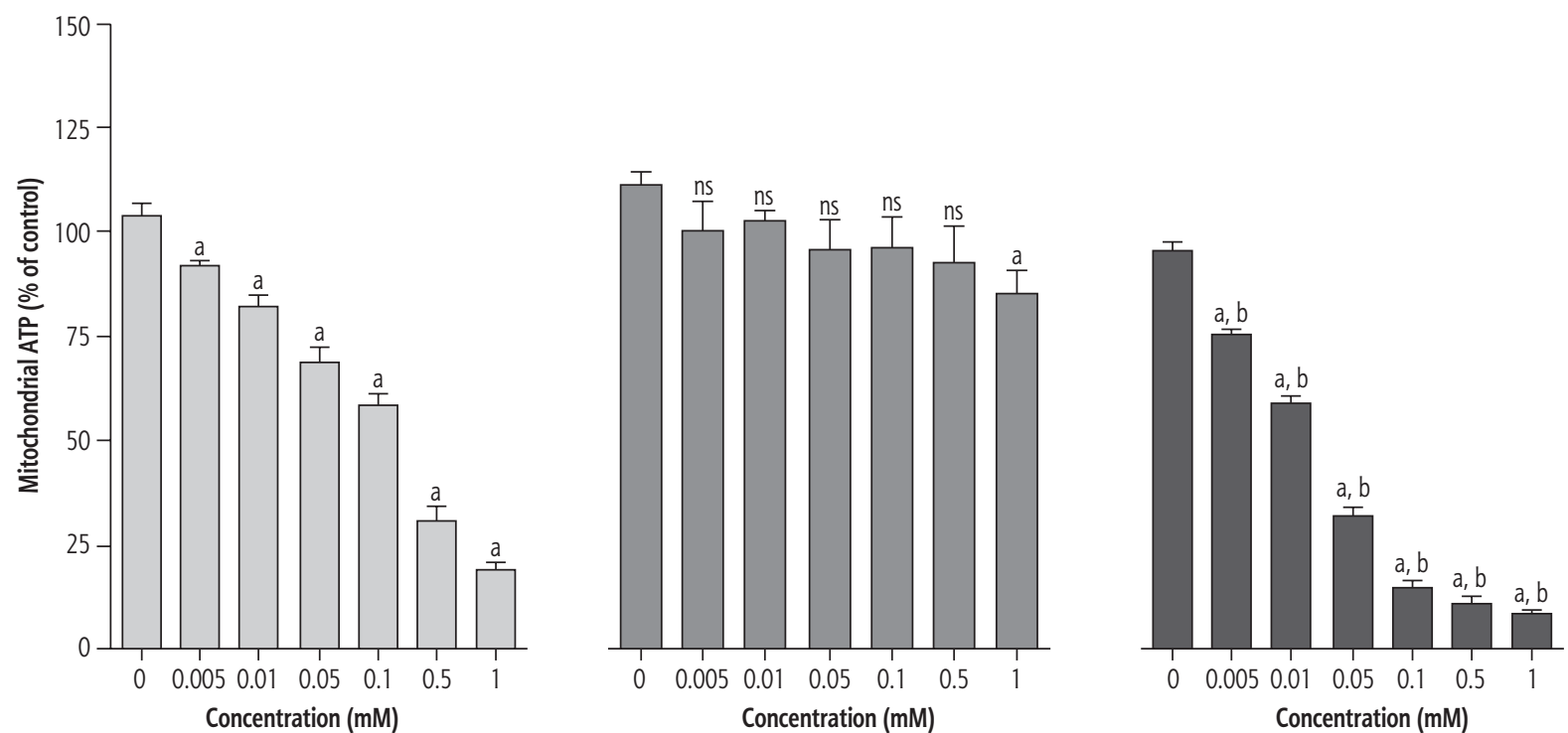

Data are shown as mean $\pm S D(n=8)$. Indicates significantly different as compared with control $(0 \mathrm{mM})(p<0.01)$. ${ }^{b} /$ ndicates significantly different as compared with the same concentration of $\mathrm{NH}_{4}^{+}$and/or $\mathrm{Mn}^{2+}-$ treated mitochondria $(\mathrm{p}<0.05)$. ns - not significant as compared with control $(0 \mathrm{mM})$.

Fig. 5. Ammonia $\left(\mathrm{NH}_{4}^{+}\right)$and manganese $\left(\mathrm{Mn}^{2+}\right)$-induced decrease in mitochondrial ATP content

Impaired liver capacity of ammonia detoxification and blood and brain ammonia levels have been strongly implicated in the pathogenesis of cirrhosis-associated HE $[4,6,54]$. Several cellular and molecular mechanisms have been identified for ammonia toxicity. Oxidative stress and its subsequent events play a major role in the mechanism of ammonia neurotoxicity [5, $55,56]$. At the cellular level, mitochondrial impairment and cellular energy (ATP) crisis are involved in the mechanism of ammonia toxicity $[8,11,12,56-58]$. Impaired mitochondria energy metabolism, significant mitochondrial permeabilization, enhanced mito- chondria-mediated ROS formation, and release of cell death mediators from cellular mitochondria are connected with the effects of ammonia on the brain tissue [8, 11, 12, 56-58] (Fig. 6).

Manganese is a trace element physiologically incorporated in the structure of several vital enzymes in the human body [19]. On the other hand, it has been found that excess Mn exposure is associated with several adverse effects, especially in the brain [20-22]. Physiologically, $\mathrm{Mn}$ is excreted in the bile [23, 33-36]. Hence, any defect in the bile flow could lead to Mn accumulation in the body [23, 33-36]. It has been found

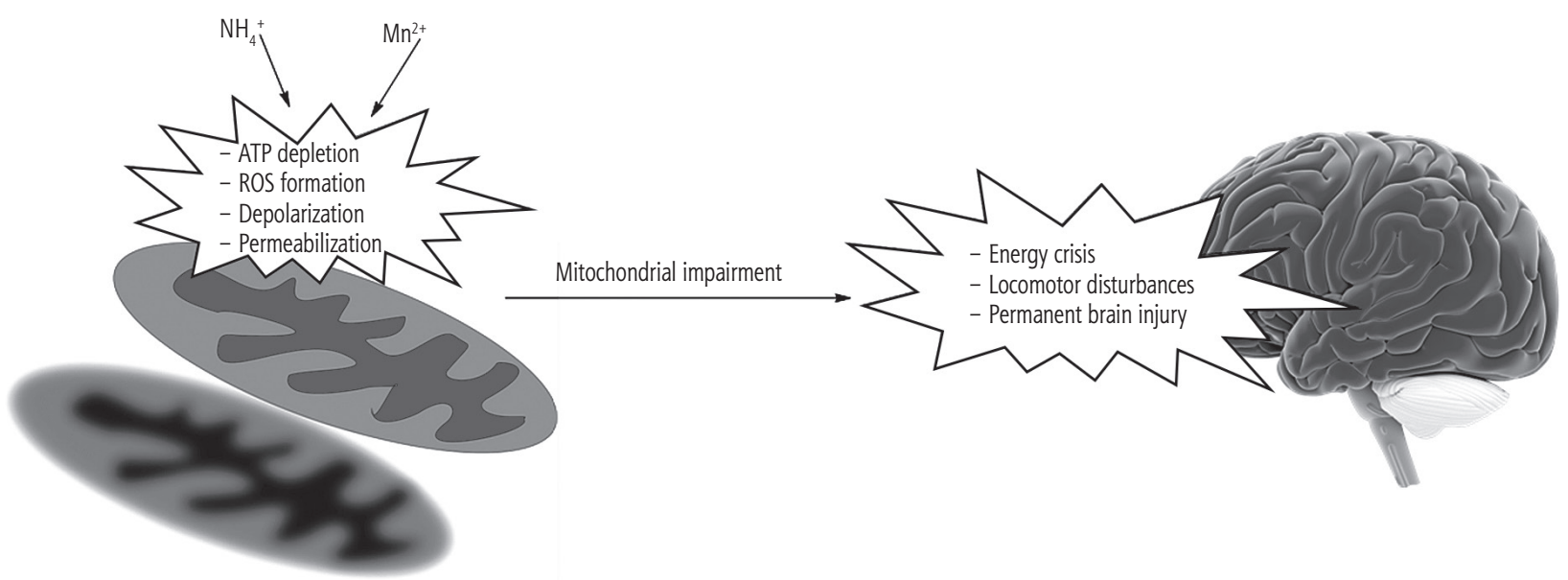

Fig. 6. Schematic representation of the additive effects of manganese and ammonia on brain mitochondrial function. Impaired brain mitochondrial function could play a critical role in CNS injury during cirrhosis and chronic hepatic encephalopathy. Brain energy crisis, disturbances in locomotor activity, coma, and permanent brain injury might ensue from hepatic encephalopathy 
that cirrhosis is associated with an elevated body $\mathrm{Mn}$ level [23, 33-36]. Up to a 7-fold increase in the blood and brain Mn level is documented in cirrhotic patients $[33,59] . \mathrm{Mn}$ is accumulated in the brain tissue, where it manifests its toxic properties. A wide range of impairment including locomotor dysfunction and mood abnormalities has been reported in association with brain Mn deposition [21, 24, 51]. It has been found that cirrhosis-associated locomotor dysfunction might be associated, at least in part, with high brain Mn level $[18,22,33,34]$.

Cellular mitochondria are among the major targets of Mn toxicity [25, 29-32]. Mn is accumulated in the mitochondrial matrix through $\mathrm{Ca}^{2+}$ transporters [60, 61]. Severe collapse of the mitochondrial membrane potential and inhibition of mitochondria respiratory chain complexes are reported in association with mitochondrial Mn exposure [25, 29-32, 60, 61].

In chronic liver injury (e.g., cirrhosis) both $\mathrm{Mn}$ and ammonia are present in the brain tissue. As mentioned, cellular mitochondria are affected by ammonia and $\mathrm{Mn}$. In the current study, it was found that lower levels of ammonia become more toxic in the presence of $\mathrm{Mn}$. A more significant decrease in brain mitochondria dehydrogenase activity, the collapse of mitochondrial membrane potential, mitochondrial permeabilization, and depletion of mitochondrial ATP content were detected when brain mitochondria were co-exposed to both Mn and ammonia (Fig. 6). On the other hand, Mn adversely affected mitochondrial function even at low concentrations $(0.01 \mathrm{mM})$. These data suggest the importance of brain Mn accumulation in cirrhosis-associated CNS complications. This might indicate the importance of effective therapeutic options which consider strategies against both Mn and ammonia (Fig. 6). As mitochondria are among the major cellular targets affected by ammonia and $\mathrm{Mn}$, regulating mitochondrial function and preserving cellular energy (ATP) status at a higher level might affect $\mathrm{Mn}$ and ammonia neurotoxicity in cirrhotic patients.

Some studies have mentioned the importance of $\mathrm{Mn}$ chelation therapy as an option against $\mathrm{Mn}$ neurotoxicity [62, 63]. However, the effectiveness of such strategies has been questioned. Chelation therapy might disturb the homeostasis of other metals in the human body or lead to complications such as nephrotoxicity. Hence, other ancillary therapeutic options are required to manage central nervous system complications associated with manganese or ammonia. Some safe and clinically applicable chemicals have been identified to protect the brain in situations such as HE [64-68]. Hence, mitigating brain oxidative stress and protecting cellular mitochondria could be a viable therapeutic approach against ammonia and $\mathrm{Mn}$ neurotoxicity (Fig. 6).

The data obtained in the current investigation might provide some clues that ammonia-induced mitochondrial impairment and neurotoxicity are exacerbated in the presence of Mn. This could help to improve clinical management of chronic liver injury (e.g., cirrhosis)-associated CNS complications.

\section{Acknowledgments}

This work was financially supported by a grant of the Vice Chancellor of Research Affairs of Shiraz University of Medical Sciences, Shiraz, Iran (Grant \#9501-36-12832). The authors thank Pharmaceutical Sciences Research Center of Shiraz University of Medical Sciences for technical assistance in carrying out the current study.

\section{Disclosure}

Authors report no conflict of interest.

\section{References}

1. Felipo V. Hepatic encephalopathy: effects of liver failure on brain function. Nat Rev Neurosci 2013; 14: 851-858.

2. Shawcross D, Jalan R. The pathophysiologic basis of hepatic encephalopathy: central role for ammonia and inflammation. Cell Mol Life Sci 2005; 62: 2295-2304.

3. Oja SS, Saransaari P, Korpi ER. Neurotoxicity of ammonia. Neurochem Res 2017; 42: 713-720.

4. Braissant $\mathrm{O}$, McLin VA, Cudalbu C. Ammonia toxicity to the brain. J Inherit Metab Dis 2013; 36: 595-612.

5. Norenberg M. Oxidative and nitrosative stress in ammonia neurotoxicity. Hepatology 2003; 37: 245-248.

6. Bosoi CR, Rose CF. Identifying the direct effects of ammonia on the brain. Metab Brain Dis 2009; 24: 95-102.

7. Albrecht J, Jones EA. Hepatic encephalopathy: molecular mechanisms underlying the clinical syndrome. J Neurol Sci 1999; 170: 138-146.

8. Wang Q, Wang Y, Yu Z, et al. Ammonia-induced energy disorders interfere with bilirubin metabolism in hepatocytes. Arch Biochem Biophys 2014; 555-556: 16-22.

9. Felipo V, Butterworth RF. Mitochondrial dysfunction in acute hyperammonemia. Neurochem Int 2002; 40: 487-491.

10. Rama Rao KV, Jayakumar AR, Norenberg MD. Ammonia neurotoxicity: role of the mitochondrial permeability transition. Metab Brain Dis 2003; 18: 113-127.

11. Norenberg MD, Rama Rao KV, Jayakumar AR. Ammonia neurotoxicity and the mitochondrial permeability transition. J Bioenerg Biomembr 2004; 36: 303-307.

12. Bai G, Rama Rao KV, Murthy CRK, et al. Ammonia induces the mitochondrial permeability transition in primary cultures of rat astrocytes. J Neurosci Res 2001; 66: 981-991.

13. Ott P, Clemmesen O, Larsen FS. Cerebral metabolic disturbances in the brain during acute liver failure: from hyperammonemia to energy failure and proteolysis. Neurochem Int 2005; 47 : $13-18$. 
14. O'Connor J-E, Costell M, Grisolía S. Protective effect of L-carnitine on hyperammonemia. FEBS Letters 1984; 166: 331-334.

15. Samuelsson C, Hillered L, Zetterling M, et al. Cerebral glutamine and glutamate levels in relation to compromised energy metabolism: a microdialysis study in subarachnoid hemorrhage patients. J Cereb Blood Flow Metab 2007; 27: 1309-1317.

16. Lai JC, Cooper AJ. Neurotoxicity of ammonia and fatty acids: differential inhibition of mitochondrial dehydrogenases by ammonia and fatty acyl coenzyme a derivatives. Neurochem Res 1991; 16: 795-803.

17. Quero JC, Hartmann IJ, Meulstee J, et al. The diagnosis of subclinical hepatic encephalopathy in patients with cirrhosis using neuropsychological tests and automated electroencephalogram analysis. Hepatology 1996; 24: 556-560.

18. Groeneweg M, Quero JC, De Bruijn I, et al. Subclinical hepatic encephalopathy impairs daily functioning. Hepatology 1998; 28: 45-49.

19. Aschner JL, Aschner M. Nutritional aspects of manganese homeostasis. Mol Aspects Med 2005; 26: 353-362.

20. Sidoryk-Wegrzynowicz M, Aschner M. Role of astrocytes in manganese mediated neurotoxicity. BMC Pharmacol Toxicol 2013; $14: 23$

21. Rivera-Mancía S, Ríos C, Montes S. Manganese accumulation in the CNS and associated pathologies. Biometals 2011; 24: 811825.

22. Peres TV, Schettinger MRC, Chen P, et al. Manganese-induced neurotoxicity: a review of its behavioral consequences and neuroprotective strategies. BMC Pharmacol Toxicol 2016; 17: 57.

23. Mignarri A, Federico A. From the liver to the brain: manganese matters: focus on cirrhosis-related parkinsonism. Neurol Sci 2014; 35: 521-522.

24. Dodd CA, Ward DL, Klein BG. Basal Ganglia accumulation and motor assessment following manganese chloride exposure in the C57BL/6 mouse. Int J Toxicol 2005; 24: 389-397.

25. Zhang F, Xu Z, Gao J, et al. In vitro effect of manganese chloride exposure on energy metabolism and oxidative damage of mitochondria isolated from rat brain. Environ Toxicol Pharmacol 2008; 26: 232-236.

26. Milatovic D, Zaja-Milatovic S, Gupta RC, et al. Oxidative damage and neurodegeneration in manganese-induced neurotoxicity. Toxicol Appl Pharmacol 2009; 240: 219-225.

27. Dobson AW, Erikson KM, Aschner M. Manganese neurotoxicity. Ann N Y Acad Sci 2004; 1012: 115-128.

28. Chen C-J, Liao S-L. Oxidative stress involves in astrocytic alterations induced by manganese. Exp Neurol 2002; 175: 216-225.

29. Gunter TE, Gavin CE, Gunter KK. The role of mitochondrial oxidative stress and ATP depletion in the pathology of manganese toxicity. Metal ion in stroke. Springer, New York, NY 2012; 591-606.

30. Yin Z, Aschner JL, dos Santos AP, Aschner M. Mitochondrial-dependent manganese neurotoxicity in rat primary astrocyte cultures. Brain Res 2008; 1203: 1-11.

31. Verity MA. Manganese neurotoxicity: a mechanistic hypothesis. Neurotoxicology 1999; 20: 489-497.

32. Gunter TE. Manganese and mitochondrial function. In: Collins JF (ed.). Molecular, Genetic, and Nutritional Aspects of Major and Trace Minerals. Academic Press, Boston 2017; 389-396.

33. Rose C, Butterworth RF, Zayed J, et al. Manganese deposition in basal ganglia structures results from both portal-systemic shunting and liver dysfunction. Gastroenterology 1999; 117: 640-644.

34. Montes S, Alcaraz-Zubeldia M, Muriel P, Rios C. Striatal manganese accumulation induces changes in dopamine metabolism in the cirrhotic rat. Brain Res 2001; 891: 123-129.
35. Krieger D, Krieger S, Theilmann L, et al. Manganese and chronic hepatic encephalopathy. Lancet 1995; 346: 270-274.

36. Görg B, Qvartskhava N, Bidmon H-J, et al. Oxidative stress markers in the brain of patients with cirrhosis and hepatic encephalopathy. Hepatology 2010; 52: 256-265.

37. Caro AA, Adlong LW, Crocker SJ, et al. Effect of garlic-derived organosulfur compounds on mitochondrial function and integrity in isolated mouse liver mitochondria. Toxicol Lett 2012; 214: 166-174.

38. Iglesias-González J, Sánchez-Iglesias S, Beiras-Iglesias A, et al. A simple method for isolating rat brain mitochondria with high metabolic activity: effects of EDTA and EGTA. J Neurosci Methods 2013; 213: 39-42.

39. Zhao P, Kalhorn TF, Slattery JT. Selective mitochondrial glutathione depletion by ethanol enhances acetaminophen toxicity in rat liver. Hepatology 2002; 36: 326-335.

40. Eftekhari A, Ahmadian E, Azarmi Y, et al. In vitro/vivo studies towards mechanisms of risperidone-induced oxidative stress and the protective role of coenzyme Q10 and N-acetylcysteine. Toxicol Mech Methods 2016; 26: 520-528.

41. Eftekhari A, Ahmadian E, Azarmi Y, et al. The effects of cimetidine, $\mathrm{N}$-acetylcysteine, and taurine on thioridazine metabolic activation and induction of oxidative stress in isolated rat hepatocytes. Pharm Chem J 2018; 51: 965-969.

42. Ahmadian E, Eftekhari A, Fard JK, et al. In vitro and in vivo evaluation of the mechanisms of citalopram-induced hepatotoxicity. Arch Pharm Res 2017; 40: 1296-1313.

43. Marroquin L, Swiss R, Will Y. Identifying compounds that induce opening of the mitochondrial permeability transition pore in isolated rat liver mitochondria. Curr Protoc Toxicol 2014; 60: 25.4.1-17.

44. Niknahad H, Jamshidzadeh A, Heidari R, et al. Paradoxical effect of methimazole on liver mitochondria: In vitro and in vivo. Toxicol Lett 2016; 259: 108-115.

45. Mosmann T. Rapid colorimetric assay for cellular growth and survival: application to proliferation and cytotoxicity assays. J Immunol Methods 1983; 65: 55-63.

46. Ahmadian E, Babaei H, Mohajjel Nayebi A, et al. Venlafaxine-induced cytotoxicity towards isolated rat hepatocytes involves oxidative stress and mitochondrial/lysosomal dysfunction. Adv Pharm Bull 2016; 6: 521-530.

47. Bradford MM. A rapid and sensitive method for the quantitation of microgram quantities of protein utilizing the principle of protein-dye binding. Anal Biochem 1976; 72: 248-254.

48. Held P. Luminescent determination of ATP concentrations using the Clarity ${ }^{\mathrm{mat}}$ Luminescence Microplate Reader. Nat Methods 2006.

49. Heidari R, Ghanbarinejad V, Ommati MM, et al. Regulation of mitochondrial function and energy metabolism: A primary mechanism of cytoprotection provided by carnosine. Trends Pharm Sci 2018; 4.

50. Heidari R, Niknahad H, Sadeghi A, et al. Betaine treatment protects liver through regulating mitochondrial function and counteracting oxidative stress in acute and chronic animal models of hepatic injury. Biomed Pharmacother 2018; 103: 75-86.

51. Forton DM, Patel N, Prince M, et al. Fatigue and primary biliary cirrhosis: association of globus pallidus magnetisation transfer ratio measurements with fatigue severity and blood manganese levels. Gut 2004; 53: 587-592.

52. Bajaj JS, White MB, Unser AB, et al. Cirrhotic patients have good insight into their daily functional impairment despite prior hepatic encephalopathy: comparison with PROMIS norms. Metab Brain Dis 2016; 31: 1199-1203. 
53. Cordoba J, Cabrera J, Lataif L, et al. High prevalence of sleep disturbance in cirrhosis. Hepatology 1998; 27: 339-345.

54. Dhiman RK, Saraswat VA, Sharma BK, et al. Minimal hepatic encephalopathy: Consensus statement of a working party of the Indian National Association for Study of the Liver. J Gastroenterol Hepatol 2010; 25: 1029-1041.

55. Norenberg MD, Jayakumar AR, Rama Rao KV. Oxidative stress in the pathogenesis of hepatic encephalopathy. Metab Brain Dis 2004; 19: 313-329.

56. Norenberg MD, Rao KVR, Jayakumar AR. Signaling factors in the mechanism of ammonia neurotoxicity. Metab Brain Dis 2008; 24: 103-117.

57. Rama Rao KV, Jayakumar AR, Norenberg MD. Ammonia neurotoxicity: role of the mitochondrial permeability transition. Metab Brain Dis 2003; 18: 113-127.

58. Felipo V, Butterworth RF. Neurobiology of ammonia. Prog Neurobiol 2002; 67: 259-279.

59. Butterworth RF, Spahr L, Fontaine S, Layrargues GP. Manganese toxicity, dopaminergic dysfunction and hepatic encephalopathy. Metab Brain Dis 1995; 10: 259-267.

60. Gavin CE, Gunter KK, Gunter TE. Manganese and calcium transport in mitochondria: implications for manganese toxicity. Neurotoxicology 1999; 20: 445-453.

61. Gavin CE, Gunter KK, Gunter TE. Mn2+ sequestration by mitochondria and inhibition of oxidative phosphorylation. Toxicol Appl Pharmacol 1992; 115: 1-5.

62. Herrero Hernandez E, Discalzi G, Valentini C, et al. Follow-up of patients affected by manganese-induced Parkinsonism after treatment with CaNa2EDTA. Neurotoxicology 2006; 27: 333339.

63. Tuschl K, Mills PB, Clayton PT. Manganese and the brain. Int Rev Neurobiol 2013; 110: 277-312.

64. Jamshidzadeh A, Abdoli N, Niknahad H, et al. Taurine alleviates brain tissue markers of oxidative stress in a rat model of hepatic encephalopathy. Trends Pharm Sci 2017; 3: 181-192.

65. Jamshidzadeh A, Heidari R, Abasvali M, et al. Taurine treatment preserves brain and liver mitochondrial function in a rat model of fulminant hepatic failure and hyperammonemia. Biomed Pharmacother 2017; 86: 514-520.

66. Jamshidzadeh A, Niknahad H, Heidari R, et al. Carnosine protects brain mitochondria under hyperammonemic conditions: Relevance to hepatic encephalopathy treatment. Pharmanutrition 2017; 5: 58-63.

67. Jamshidzadeh A, Abdoli N, Niknahad H, et al. Carnosine supplementation mitigates brain tissue markers of oxidative stress in a rat model of fulminant hepatic failure. Trends Pharma Sci 2017; 3: 149-160.

68. Jamshidzadeh A, Heidari R, Latifpour Z, et al. Carnosine ameliorates liver fibrosis and hyperammonemia in cirrhotic rats. Clin Res Hepatol Gastroenterol 2017; 41: 424-434. 